Research Article

\title{
Rural women's socio-demographic and cultural determinants on contraceptive uptake in The Gambia: community-based cross-sectional study
}

\author{
Amadou Barrow 1,2, (D) \\ ${ }^{1}$ Department of Public \& Environmental Health, School of Medicine \& Allied Health Sciences, University of \\ The Gambia, Kanifing, The Gambia \\ ${ }^{2}$ School of Public Health, Gambia College, Brikama Campus, Brikama, The Gambia \\ *Correspondence: abarrow@utg.edu.gm
}

How to cite this paper: Barrow, A. (2021). Rural women's socio-demographic and cultural determinants on contraceptive uptake in The Gambia: community-based crosssectional study. Current Research in Public Health, 1(1), 23-39. Retrieved from https://www.scipublications.com/journal/index.php/crph/article/view/178

\begin{abstract}
Background: Family planning is one of the key cornerstones of safe parenthood and a reproductive rights issue. In underdeveloped nations, women experiencing unmet FP needs formed a considerable proportion of all women of reproductive age and are ongoing public health concerns in The Gambia. The study was set out to explore the influence of socio-demographic and cultural factors on contraceptive uptake among rural women in The Gambia. Methods: The study used a community-based cross-sectional analytical design. A multistage sampling strategy, comprising simple random and cluster sampling, was utilized to obtain a sample of 634 childbearing women (15-49 years) from rural Gambia's sampled clusters. Data collection was conducted using pre-tested structured interview questionnaires. The association was examined using chi-square/fisher's exact test with a significance level set at $p<0.05$. Binary logistic regression analysis was performed to examine the effect of socio-demographic and cultural determinants on uptake of contraceptives, with corresponding computed adjusted odds ratios (aOR). IBM SPSS version 25 was used for data entry and analysis. Results: The uptake of contraceptives among the study participants was $30.4 \%$. The total demand for FP was 59.4\% while the satisfaction of demand for FP was $57.6 \%$. The significant predictors of FP uptake were the age of women $(\mathrm{aOR}=1.097, \mathrm{p}=0.014)$, reason for using FP ( $\mathrm{aOR}=1.139, \mathrm{p}=0.011)$, use of contraceptives before $(\mathrm{aOR}=24.416, \mathrm{p}<0.001)$ and reason for not discussing FP with a partner ( $\mathrm{aOR}=1.787, \mathrm{p}=0.029)$. Conclusion: The study showed low contraceptive uptake among women in rural communities. Thus, spousal communications on FP concerns are key intermediate steps towards eventual acceptance and sustained usage of FP services. The program should focus on improving access to and availability of FP services in rural areas. The program should prioritize addressing women's needs through consistent community-based interventions including targeted home visits.
\end{abstract}

Keywords: Contraceptives uptake, rural women, Gambia, women of reproductive-age

\section{Introduction}

Family planning (FP) methods have been found as an efficient approach to reducing fertility and are therefore widely supported to decrease population growth, particularly in poor nations [1]. Through the prevention of undesired pregnancies, family planning has numerous health benefits [2-4]. Some of these benefits include a decrease in the transmission of HIV to newborns [5], a decrease in the number of women who die or suffer from adverse health outcomes [6], a decrease in the number of newborns, infants, and children's mortality [7, 8], and those who resort to unsafe abortions [6]. More than 1.8 billion young people live in underdeveloped nations, with nearly $90 \%$ of them [9] being under the age of 24. Most people begin to explore their sexuality during this time period, which is between the ages of 15 and 24 [10]. It is documented 
that unexpected pregnancies, unsafe abortions, high-risk pregnancies, and teenage pregnancies are all reduced when contraception is used more widely $[1,11,12]$. Unsafe abortions pose severe morbidity and mortality risks to women of all ages in most developing countries [13]. Averting unwanted pregnancies has many health advantages [14-16]. Women (and men) who can postpone childbearing will have more possibilities in terms of jobs and education. They will also have less reliance on often unsafe abortion [6]. Condom use, for example, has been recognized for reducing the incidence of STIs, including HIV/AIDS [1]. In 2019, there are roughly 1.9 billion women of childbearing age (15-49) [17]. A total of 842 million people use contraception currently, whereas 270 million individuals have unmet contraceptive requirements [17, 18]. In 2019, 75.7 percent of FP was required globally to satisfy SDG indicator 3.7.1 [17]. SDG 5 advocates for gender equality as well as women and girls empowerment [17].

In developing countries, the use of modern health care such as maternal health services including use of contraceptives can be influenced by the socio-demographic characteristics of women such as education, age of women, income and occupation [19-21]. Additional factors such as low awareness level and high parity were also found to influence FP uptake [22, 23]. Social and cultural norms also influence the adoption of harmful reproductive health behaviors. Poor women's ability to think for themselves and make informed decisions is typically underestimated in highly stratified societies [24, 25]. Many African tribes had sex taboo for decades, according to some researches [26, 27]. Contraception information was not appropriately tailored to local beliefs and practices. Language or ideology differences between providers and clients can sometimes generate communication issues [28]. The household and community in which the individual lives, as well as the features of the health services accessible in the community, must be considered when determining utilization of reproductive health services [26]. Women frequently cite their partners' attitudes as a factor for not starting or continuing contraception [29]. The patriarchal structure of African civilizations (particularly The Gambia) leaves little opportunities for discussion when it comes to women's reproductive health [26].

Recently, The Gambia's National Indicators for FP satisfaction with modern contraception were $37.6 \%$ in 2017 [30] and 43.9 percent in 2019 [31], with rural areas reporting 40.3 percent satisfaction with FP and a cumulative marginal difference of $5.2 \%$ lower than urban areas [31]. At the Local Government Area (LGA) level, Basse (22.5\%), Mansakonko (37.9\%), and Kuntaur (39.9\%) satisfied the least FP demands, which is slightly more than the 2015 and 2017 statistics [30-32]. These LGAs are considered the lowest in terms of FP services uptake in the country. The Gambia has a Total Fertility Rate (TFR) of 5.6, with 6.8 in rural areas and 4.7 in urban areas [33]. There are only $9 \%$ of currently married women using any method of contraception, while $8 \%$ use modern methods and $1 \%$ traditional methods [33]. The prevalence of modern contraceptive method use in urban areas is three times higher than in rural areas (12\% versus $4 \%$, respectively) [33]. According to the Maternal and Child Nutrition and Health Results (MCNHR) baseline survey in 2015 reported that the use of any FP methods was low, particularly in Upper River Region and Central River Region where only $14 \%$ and $13 \%$ of women reported using any FP methods [34]. The regional variability could be attributed to the multiplicity of socio-demographic and socio-cultural determinants such as religion, ethnicity, cultural practices, patriarchal societies in nature, female education and FP delivery mechanisms.

There are very limited studies on uptake of FP among women of reproductive age (including female adolescents) in The Gambia. Thus, this study aimed to understand the influence of socio-demographic and socio-cultural factors on the uptake of contraceptives among rural women in The Gambia. 


\section{Methods}

\subsection{Study design and population}

A community-based analytical cross-sectional study design was conducted from December 2016 to January 2017. The study focused on examining the prevalence and understanding of socio-demographic, cultural, and proximate factors influencing uptake of FP. Structured questionnaires were administered to women of reproductive age (15-49 years old) across the four provincial LGAs in The Gambia.

\subsection{Study settings}

The study was conducted in Kerewan, Kuntaur, Janjanbureh, and Basse LGAs. Each of the LGAs are headed by a Governor. Basse LGA has 239,916 residents with a growth rate of 2.7 percent [35]. It has a female population of 115,960 (48.3\%) [35]. Kerewan LGA has a population of 221,054 with 6.3 percent fertility rate [33]. It has a female population of $116,123(51.8 \%)$. Janjanburreh LGA has a population of 126,910 with $7 \%$ fertility rate [33]. It has a female population of 65,909 (51.9\%). Kuntaur LGA has 99,108 residents with female population of $51,875(52.3 \%)$ [33]. Farming and business are the two main occupations of inhabitants from all the four LGAs.

\subsection{Study variables}

\subsubsection{Dependent variables}

The dependent variables of interest in this study was uptake of FP. Uptake of FP services was described as the current use of any FP method.

\subsubsection{Independent variables}

In this study, the independent variables for socio-demographics included age: 15 19, 20 - 24, 25 - 29, 30 - 34, 35 - 39, 40 - 44, 45 - 49; place of residence: Kerewan, Kuntaur, Janjanbureh, Basse; educational level: never attended any school, Arabic education, primary education, secondary education, tertiary education; occupation: exclusively housewife, self-employed, farming, student, trading, civil servant, Muslim religious teacher; marital status: married or in union, single; income: less than D2000, D2001 - D4000, more than D4000; age at first pregnancy: $12-18,19-24,25-30$; parity: $0-4,5-8,9+$; religion: Muslim, Christian, traditional African religion; ethnicity: Mandinka, Fula, Sarahule, Wollof, Manjago, Serere, Aku; partner's education: never attended any school, Arabic education, primary education, secondary education, tertiary education; partner's occupation: civil servant, farming, self-employed, student, trading, retired, travelled abroad; mother's education: never attended any school, Arabic education, primary education, secondary education, tertiary education; and father's education: never attended any school, Arabic education, primary education, secondary education, tertiary education. Furthermore, the variables for socio-cultural \& proximate factors were society's support for FP usage: yes/no/I don't know; traditional belief against FP: yes/no/I don't know; partner support: yes/no/I don't know; decision on it uptake: husband/partner alone, wife alone, both wife and husband/partner, healthcare providers, not using contraceptives; its harmful effects: yes/no/I don't know; benefits: yes/no/I don't know; affordability: yes/no; frequency of sex: every time (everyday), most times (>once per week), occasionally (at least twice per month), rarely, never; partners support: yes/no; and decision on desire number of children: husband/partner, myself, family/close relatives, parents, not in any relationship/marriage, God decides. 


\subsection{Inclusion and Exclusion Criteria}

This study comprises women (15-49 years old), married or unmarried, and of any ethnic group or national origin who were present and accepted to enroll during the research. Women who refused to partake in the research due to health/mental conditions that made obtaining explicit consent or conducting the interview impossible, or who are not reproductively competent, including those who have undergone surgical procedures such as hysterectomy or tubal ligation, were excluded from the study.

\subsection{Sample size determination and selection}

The sample size for this research was derived using Abramson and Gahlinger's 2002 formula for estimating single proportions [36].

$$
\mathrm{n}=\frac{\mathrm{p}(1-\mathrm{p}) \times \mathrm{Z}_{\propto}^{2}}{\mathrm{~d}^{2}} \times 2
$$

This sample size formula was used: $\mathrm{n}$ is the minimum sample size, $Z_{\propto}^{2}$ is the standard normal deviate, equals to 1.96 at $95 \%$ confidence level, $\mathrm{p}$ is the proportion of the target population with prevalence at $25 \%$ [33]) and $d^{2}$ is the degree of desired accuracy at 0.05 with a design effect of 2: This sample size formula was used:

$$
\mathrm{n}=(0.25 \times 0.75 \times(1.96) 2) /(0.05) 2 \times 2=576 .
$$

To make up for the non-response rate, a $10 \%$ of computed sample size was added to have a total of 634 recruited women for the study. The study sample was selected via multistage sampling. It was completed in four stages: Stage 1 consisted of selecting two districts from each of the four provincial LGAs. The study chose eight districts (two for each LGA) through simple randomization technique. Stage 2 chose a Primary Health Care (PHC) circuit in each of the selected districts using a simple randomization. The number of PHC circuits chosen was proportional to the district sample size. Stage 3 involved random sampling within PHC circuits to choose target communities. Finally, a cluster selection technique within the specified communities was employed to choose study participants. Since the Local Government Act of The Gambia divides each community into wards (kabilo), they were deemed clusters and all eligible subjects were recruited accordingly.

\subsection{Data collection Instruments and Methods}

A pre-tested, structured questionnaire was used to interview a representative sample of 634 women of reproductive age $(15-49)$ in the four LGAs. The questionnaire elicited information on their socio-demographic, cultural, and related characteristics; uptake of FP was also investigated. The data collection was conducted in major local languages (Mandinka, Fula, Wolof, and Serahule) in The Gambia. The researcher was actively engaged in the collecting, cross-checking, cleaning, and analysis of data. Prior to data collection, the instruments were pre-tested on women (15-49) from provinces that were not selected for the study. To determine reliability, the Cronbach's Alpha test (0.89) was used. Each completed questionnaire was re-checked immediately following the interview to rectify incorrect responses and to determine the questionnaire's appropriateness, content accuracy, and completeness, as well as the time required to complete the questionnaire. The structured questionnaire was assessed to establish its suitability for the study by screening for any ambiguities and inaccuracies.

\subsection{Data analysis}

All data entry and analysis were performed using IBM SPSS version 25. The data was first examined for the frequency distributions of the socio-demographic, socio-cultural and related variables among the subjects and further used chi-square or Fisher's exact tests 
between outcome and predictor variables. All independent variables associated with outcome variable at $\mathrm{p}<0.15$ were subsequently included into a binary logistic regression model. The model was used to examine associations using computed adjusted odds ratios at $95 \%$ confidence interval and a p-value $<0.05$ to declare statistical significant associations.

\subsection{Ethical Considerations}

The study participants' privacy and anonymity were preserved throughout the duration of the research. The College of Medical Sciences Research Ethics Committee (Ref: CMS/REC/01/COL.3/006) at the University of Benin granted ethical approval. Additional ethical permission was acquired from the Director of Health Services of The Gambia's Ministry of Health and University of The Gambia's Research and Publication Committee (Ref: \#R017 040). Women (signed or thumb-printed) gave written consent, as did parents of those aged 15 to 17.

\section{Results}

A total of 634 women of childbearing age (15 - 49 years) in rural Gambia were recruited for the study with all of them participating, thus, giving a response rate of $100 \%$. Participants from Basse LGA constituted $220(34.7 \%)$, Kerewan LGA constituted 205 (32.3\%), Janjanbureh LGA constituted 117 (18.5\%) and Kuntaur LGA constituted 92 (14.5\%).

\subsection{Prevalence of contraceptive uptake}

Of all the participants, 193 (30.4\%) reported being currently using an FP method while 441(69.6\%) were not as shown in Figure 1. In terms of specific FP methods currently using, 113 (58.5\%) reported Injectables (depo-provera. noristerat \& norigynon), followed by pills (progesterone, combined) which constituted 85 (44.0\%) from the total current FP users as shown in Figure 2. Prolonged breastfeeding and traditional methods were reported $15(7.8 \%)$ and $13(6.7 \%)$ respectively. Other methods such as suppositories, emergency contraceptives, female sterilization, coitus interruptus and periodic abstinence were all reported 1 (0.5) as per method currently using at the time of the study.

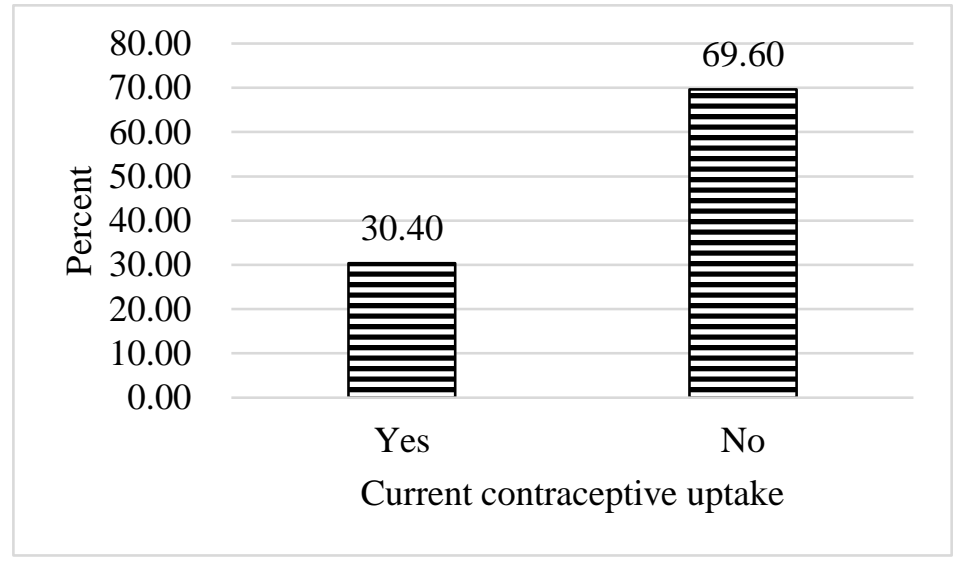

Figure 1. Current uptake of contraceptives. 


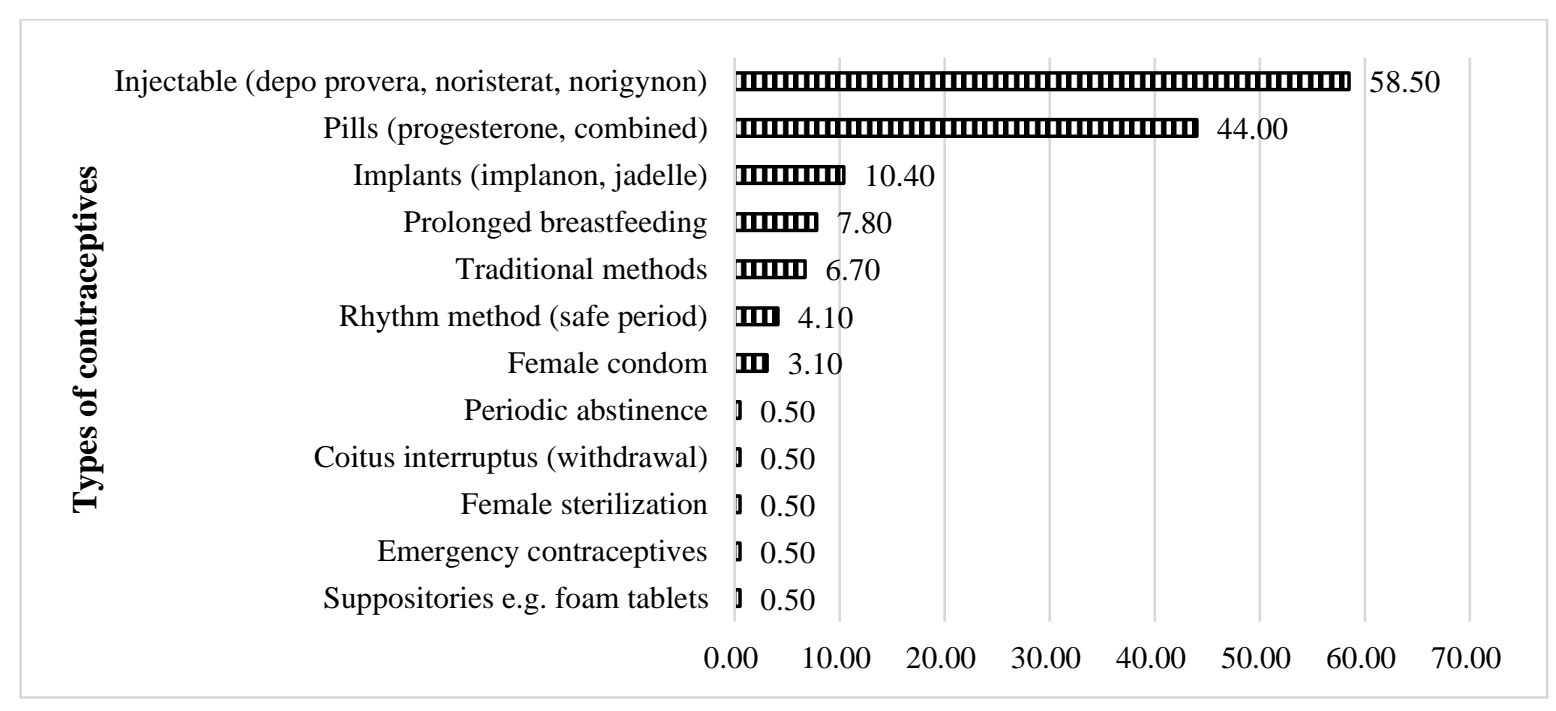

Figure 2. Types of contraceptives currently use.

At the level of kerewan LGA, Farafenni recorded a higher percentage $35.8 \%(38 / 106)$ compared to Kerewan 19.2\% (19/99) as shown in Table 1. Kuntaur community has a higher percentage $50.7 \%$ (37/73) compared to Bansang 26.4\% (24/91) and Kulari with the percentage prevalence of $21.9 \%(21 / 96)$.

Table 1. Prevalence of Contraceptive uptake across the communities in the LGAs

\begin{tabular}{cccc}
\hline \multirow{2}{*}{ LGAs } & Communities & \multicolumn{2}{c}{ Current use of contraceptives } \\
\cline { 3 - 4 } Kerewan & Kerewan & Yes n (\%) & No n (\%) \\
& Farafenni & $38(19.2)$ & $68(80.8)$ \\
\multirow{2}{*}{ Kuntaur } & Chamen & $7(31.8)$ & $15(68.2)$ \\
\multirow{2}{*}{ Janjanbureh } & Kuntaur & $37(50.7)$ & $36(49.3)$ \\
& Janjanbureh & $17(65.4)$ & $9(34.6)$ \\
\multirow{2}{*}{ Basse } & Bansang & $24(26.4)$ & $67(73.6)$ \\
& Kulari & $21(21.9)$ & $75(78.1)$ \\
& Basse & $30(24.8)$ & $91(75.2)$ \\
\hline
\end{tabular}

\subsection{Socio-demographic factors associated with contraceptive uptake}

Table 2 summarizes the analysis of socio-demographic factors influencing FP uptake. The study revealed that majority $43(22.1 \%)$ and $60(33.9 \%)$ of the women were within 20 - 24 and 25 - 29 years of age respectively were currently using contraceptives. There is a significant relationship between participants' age and their FP uptake as indicated in Fisher's exact test results $(p<0.001)$. The study revealed certain socio-demographic variables which were statistically significant such as women's educational background $\left(\chi^{2}=\right.$ 12.573, $\mathrm{df}=4, \mathrm{p}=0.014)$, monthly income $\left(\chi^{2}=16.322, \mathrm{df}=2, \mathrm{p}<0.001\right)$, parity $\left(\chi^{2}=13.768, \mathrm{df}=\right.$ $2, \mathrm{p}=0.001)$, women desire to have a baby later or not at all $\left(\chi^{2}=9.028, \mathrm{df}=3, \mathrm{p}=0.029\right)$, women desire to use FP to delay pregnancy in the future $\left(\chi^{2}=6.691, \mathrm{df}=2, \mathrm{p}=0.035\right)$, desire to be using FP for spacing or limiting $\left(\chi^{2}=7.352, \mathrm{df}=1, \mathrm{p}=0.007\right)$, marital status $\left(\chi^{2}=34.437\right.$, $\mathrm{df}=1, \mathrm{p}=<0.001)$, partners' educational level $\left(\chi^{2}=32.111, \mathrm{df}=4, \mathrm{p}<.001\right)$ as well as partners' occupation $(p=0.013)$ as indicated using Fisher's exact test. 
Table 2. Prevalence of FP uptake by Socio-demographic factors

\begin{tabular}{|c|c|c|c|c|c|}
\hline \multirow[b]{2}{*}{ Socio-demographic factors } & \multicolumn{3}{|c|}{ Current use of contraceptives } & \multirow[b]{2}{*}{$\begin{array}{l}\text { Chi- } \\
\text { square }\end{array}$} & \multirow[b]{2}{*}{ p-value } \\
\hline & $\begin{array}{c}\text { Yes }(n=193) \\
n(\%)\end{array}$ & $\begin{array}{c}\text { No }(n=441) \\
n(\%)\end{array}$ & $\begin{array}{c}\text { Total }(\mathrm{N}=634) \\
\mathrm{n}(\%)\end{array}$ & & \\
\hline \multicolumn{6}{|l|}{ Age of women in years } \\
\hline $15-19$ & $10(10.8)$ & $83(89.2)$ & 93 100.0) & & $<0.001 t^{*}$ \\
\hline $20-24$ & $43(22.1)$ & $152(77.9)$ & $195(100.0)$ & & \\
\hline $25-29$ & $60(33.9)$ & $117(66.1)$ & $177(100.0)$ & & \\
\hline $30-34$ & $36(45.0)$ & $44(55.0)$ & $80(100.0)$ & & \\
\hline $35-39$ & $29(53.7)$ & $25(46.3)$ & $54(100.0)$ & & \\
\hline $40-44$ & $13(43.3)$ & $17(56.7)$ & $30(100.0)$ & & \\
\hline $45-49$ & $2(40.0)$ & $3(60.0)$ & $5(100.0)$ & & \\
\hline \multicolumn{6}{|l|}{ Educational level } \\
\hline Never attended school & $39(25.3)$ & 115 (74.7) & $154(100.0)$ & 12.573 & $0.014^{*}$ \\
\hline Arabic education & $39(23.5)$ & $127(76.5)$ & $166(100.0)$ & & \\
\hline Primary education & $49(40.2)$ & $73(59.8)$ & $122(100.0)$ & & \\
\hline Secondary education & $57(34.2)$ & $110(65.9)$ & $167(100.0)$ & & \\
\hline Tertiary education & $9(36.0)$ & $16(64.0)$ & $25(100.0)$ & & \\
\hline \multicolumn{6}{|l|}{ Can read and write } \\
\hline Yes & $91(33.3)$ & $182(66.7)$ & $273(100.0)$ & 1.893 & 0.191 \\
\hline No & $102(28.3)$ & 259 (71.7) & $361(100.0)$ & & \\
\hline \multicolumn{6}{|l|}{ Occupation } \\
\hline Exclusively housewife & $72(31.3)$ & $158(68.7)$ & $230(100.0)$ & & $0.032 t^{*}$ \\
\hline Self-employed & $10(37.0)$ & $17(63.0)$ & $27(100.0)$ & & \\
\hline Farming & $28(17.0)$ & $137(83.0)$ & $165(100.0)$ & & \\
\hline Student & $4(9.1)$ & $40(30.6)$ & $44(100.0)$ & & \\
\hline Trading & $57(50.0)$ & $57(50.0)$ & $114(100.0)$ & & \\
\hline Civil servant & $21(47.7)$ & $23(52.3)$ & $44(100.0)$ & & \\
\hline Muslim Religious Teacher & $1(10.0)$ & $9(90.0)$ & $10(100.0)$ & & \\
\hline \multicolumn{6}{|l|}{ Monthly income } \\
\hline Less than D2000 & $88(24.4)$ & $272(75.6)$ & $360(100.0)$ & 16.322 & $<0.001^{*}$ \\
\hline D2001 - D4000 & $55(34.8)$ & $103(65.2)$ & $158(100.0)$ & & \\
\hline More than D4000 & $50(43.1)$ & $66(56.9)$ & $116(100.0)$ & & \\
\hline \multicolumn{6}{|l|}{ Age at first pregnancy $(n=558)$} \\
\hline $12-18$ & $88(29.4)$ & $211(70.6)$ & $299(100.0)$ & 4.028 & 0.133 \\
\hline $19-24$ & $88(37.4)$ & $147(62.6)$ & $235(100.0)$ & & \\
\hline $25-30$ & $9(37.5)$ & $15(62.5)$ & $24(100.0)$ & & \\
\hline \multicolumn{6}{|c|}{ Mean (standard deviation) age: 18.6 (2.8) years, Median (range): 18 (12 - 30) years } \\
\hline \multicolumn{6}{|l|}{ Parity $(n=558)$} \\
\hline $0-4$ & $122(30.0)$ & $285(70.0)$ & $407(100.0)$ & 13.768 & $0.001^{*}$ \\
\hline $5-8$ & $56(40.9)$ & $81(59.1)$ & $137(100.0)$ & & \\
\hline $9+$ & $8(57.1)$ & $6(42.9)$ & $14(100.0)$ & & \\
\hline \multicolumn{6}{|c|}{ Mean (standard deviation) age: 3.5 (2.3) years, Median (range): 3 (1 - 15) years } \\
\hline \multicolumn{6}{|c|}{ Preferred number of children in her lifetime } \\
\hline $0-4$ & $41(38.3)$ & $66(61.7)$ & $107(100.0)$ & 4.300 & 0.116 \\
\hline $5-8$ & $127(29.5)$ & 303 (70.5) & $430(100.0)$ & & \\
\hline $9+$ & $25(25.8)$ & $72(74.2)$ & 97 (100.0) & & \\
\hline
\end{tabular}

Mean (standard deviation) age: 6.5 (2.0) years, Median (range): 6 (2 - 12) years 
Desired to have a baby later or not at all

want children later
No more children wanted
Want children soon
Undecided/don't know

Women currently pregnant

Yes
No

Don't know

Is the current pregnancy desired $(n=67)$

$\begin{array}{cc}\text { Intended } & 18(41.9) \\ \text { Mistimed } & 4(30.8) \\ \text { Unwanted } & 4(36.4)\end{array}$

Desire to use FP to delay pregnancy in the future

$\begin{array}{cc}\text { Yes } & 40(35.4) \\ \text { No } & 134(31.5) \\ \text { 't know } & 19(19.8)\end{array}$

Will you be using it for spacing or limiting $(n=113)$

Religion

$\begin{array}{ll}\text { Yes } & 14(23.7) \\ \text { No } & 26(48.1)\end{array}$

\section{Muslim \\ Christian}

Traditional African Religion

Ethnicity of the Respondents

Mandinka
Fula
Sarahule
Wollof
Manjago
Serere
Aku

Marital Status

$$
\begin{aligned}
& \text { Married or in union } \\
& \text { Single }
\end{aligned}
$$

Father's educational level

$$
\begin{gathered}
\text { Never attended school } \\
\text { Arabic education } \\
\text { Primary education } \\
\text { Secondary education } \\
\text { Tertiary education }
\end{gathered}
$$

Mother's educational level

Never attended school

Arabic education

Primary education

Secondary education

Tertiary education

Partners' educational level

Never attended school

Arabic education
$32(35.6)$

38 (41.8)

99 (26.8)

24 (28.6)

$26(38.8)$

$151(28.8)$

$16(38.1)$

26 (48.1)

$189(30.5)$
$4(40.0)$
$0(0.0)$

90 (30.4)

48 (31.6)

16 (19.8)

$22(36.1)$

$0(0.0)$

11 (39.3)

$6(40.0)$

193 (34.2)

$0(0.0)$

66 (28.2)

$106(30.2)$

$4(30.8)$

10 (43.5)

7 (53.8)

96 (29.0)

77 (30.2)

14 (43.8)

$6(46.2)$

$0(0.0)$

43 (26.1)

52 (23.3)

$$
\begin{gathered}
58(64.4) \\
53(58.2) \\
270(73.2) \\
60(71.4) \\
\\
41(61.2) \\
374(71.2) \\
26(61.9) \\
\\
25(58.1) \\
9(69.2) \\
7(63.6)
\end{gathered}
$$

73 (64.6)

291 (68.5)

77 (80.2)

45 (76.3)

28 (51.9)

431 (69.5)

$6(60.0)$

4 (100.0)

206 (69.6)

104 (68.4)

65 (80.2)

39 (63.9)

1 (100.0)

17 (60.7)

$9(60.0)$

$$
\begin{gathered}
90(100.0) \\
91(100.0) \\
369(100.0) \\
84(100.0)
\end{gathered}
$$

$$
\begin{gathered}
67(100) \\
525(100.0) \\
42(100) \\
43(100.0) \\
13(100.0) \\
11(100.0)
\end{gathered}
$$

9.028

$0.029^{*}$

113 (100.0)

6.691

425 (100.0)

96 (100.0)

4.075

0.130

59 (100.0)

54 (100.0)

7.352

$0.007^{*}$

$620(100.0)$

$10(100.0)$

4 (100.0)

296 (100.0)

152 (100.0)

81 (100.0)

61 (100.0)

$1(100.0)$

28 (100.0)

15 (100.0)

371 (65.8)

70 (100.0)

$564(100.0)$

70 (100.0)

34.437

$<0.001^{*}$

168 (71.8)

234 (100.0)

$0.210 \dagger$

351 (100.0)

13 (100.0)

23 (100.0)

13 (100.0)

$13(56.5)$
$6(46.2)$

331 (100.0)

255 (100.0)

32 (100.0)

13 (100.0)

3 (100.0)

7 (53.8)

3 (100.0)

165 (100.0)

223 (100.0)

$0.820+$

$0.405+$

$0.227+$

$122(73.9)$

171 (76.7) 


\begin{tabular}{|c|c|c|c|c|}
\hline Primary education & $13(35.1)$ & $24(64.9)$ & $37(100.0)$ & \\
\hline Secondary education & $41(31.3)$ & $90(68.7)$ & $131(100.0)$ & \\
\hline Tertiary education & $44(56.4)$ & $34(43.6)$ & $78(100.0)$ & \\
\hline \multicolumn{5}{|l|}{ Partners' occupation } \\
\hline Civil Servant & $62(48.8)$ & 65 (51.2) & $127(100.0)$ & $0.013 t^{*}$ \\
\hline Farming & $44(23.8)$ & $141(76.2)$ & $185(100.0)$ & \\
\hline Self employed & $30(30.9)$ & $67(69.1)$ & $97(100.0)$ & \\
\hline Student & $3(10.7)$ & $25(89.3)$ & $28(100.0)$ & \\
\hline Trading & $31(27.9)$ & $80(72.1)$ & $111(100.0)$ & \\
\hline Retired & $0(0.0)$ & $3(100.0)$ & $3(100.0)$ & \\
\hline Travelled abroad & $23(27.7)$ & $60(72.3)$ & $83(100.0)$ & \\
\hline
\end{tabular}

* =Statistical significance at $\mathrm{p}<0.05$

† Fisher's exact test

In Table 3, the multivariate analysis shows that variables in the model accounted for between $15.4 \%-21.3 \%$ of the variation observed in the outcome variable (current contraceptive use). With an increase in age, women were more likely by an odds of 1.097 to use contraceptives. This was statistically significant $(p=0.014,95 \% \mathrm{CI}=1.019-1.181)$. Women whose reason for using FP in the future will be for spacing were less likely by an odds of 0.320 to use contraceptives compared to those whose reason will be for limiting. This was statistically significant $(\mathrm{p}=0.011,95 \% \mathrm{CI}=0.133-0.771)$.

Table 3. Results of Binary Logistic Regression analysis for FP uptake among reproductive-age women by Socio-demographic factors

\begin{tabular}{|c|c|c|c|c|c|}
\hline \multirow[b]{2}{*}{ Predictors } & \multirow{2}{*}{$\begin{array}{c}\text { B (regression } \\
\text { coefficient) }\end{array}$} & \multirow[b]{2}{*}{$\begin{array}{c}\text { Adjusted Odds } \\
\text { Ratio } \\
\end{array}$} & \multicolumn{2}{|c|}{$95 \%$ C.I. for aOR } & \multirow[b]{2}{*}{ P-value } \\
\hline & & & Lower & Upper & \\
\hline Age of Respondents & 0.092 & 1.097 & 1.019 & 1.181 & $0.014^{*}$ \\
\hline \multicolumn{6}{|l|}{ Women who can read and write } \\
\hline Yes & 0.967 & 2.629 & 0.919 & 7.521 & 0.071 \\
\hline No $(\operatorname{Ref})$ & & 1 & & & \\
\hline Preferred number of children & -0.147 & 0.863 & 0.693 & 1.076 & 0.190 \\
\hline \multicolumn{6}{|c|}{ Reasons for using FP in the future } \\
\hline Spacing & -1.139 & 0.320 & 0.133 & 0.771 & $0.011^{*}$ \\
\hline Limiting (Ref) & & 1 & & & \\
\hline
\end{tabular}

Ref=Reference category, R2=15.4\% - 21.3\%, CI= Confidence Interval, * Statistical significance $\mathrm{p}<0.05$

\subsection{Socio-cultural and proximate factors associated with the uptake of FP services among the study participants}

From Table 4, the study shows that a total $271(42.7 \%)$ of the participants reported that the society supports the use of contraceptives compared to $291(45.9 \%)$ who reported that the society does not support the use of contraceptives. These differences were statistically significant $\left(\chi^{2}=10.426, \mathrm{df}=2, \mathrm{p}=0.005\right)$. A total of $173(27.4 \%)$ reported that they had their partners' support on the use of contraceptives while $282(44.7 \%)$ reported that they were not supported by their partners on the use of contraceptives. Out of those with partner's support, 97 (56.1\%) were found to be currently using contraceptives. These differences were statistically significant $\left(\chi^{2}=75.608, \mathrm{df}=2, \mathrm{p}<0.001\right)$. In terms of deciding on the 
uptake of contraceptives, the majority of the women 70 (51.9\%) were found to be using contraceptives which were a joint decision between the women and their partners while only $47(31.5 \%)$ were found to be using contraceptives on the basis of their partner's decisions only. These differences were statistically significant $\left(\chi^{2}=36.512, \mathrm{df}=4, \mathrm{p}<0.001\right)$. The study revealed that $184(42.8 \%)$ of the women were found to be using contraceptives while only $9(17.7 \%)$ were found to be using contraceptives without knowing if contraceptives are beneficial. The differences were statistically significant $\left(\chi^{2}=11.997, \mathrm{df}=1, \mathrm{p}=0.001\right)$. Majority of the women 193 (40.1\%) who reported to know about contraceptives and were found to be using FP while only 246 (57.2\%) of the women reported that they do know about contraceptives but were not using it at the time of the study. According to the Fisher's exact test, these differences were found to be statistically significant $(\mathrm{p}<0.001)$. There was a statistically significant association between women who heard of contraceptives and their uptake of contraceptives as shown in the Fisher's exact test results $(\mathrm{p}<0.001)$

Socio-cultural variables that were found to be significantly associated with contraceptive uptake includes women discussion of FP with their partners $\left(\chi^{2}=68.836, \mathrm{df}=1\right.$, $\mathrm{p}<0.001)$, reasons for not discussing with their partners $\left(\chi^{2}=33.405\right.$, $\left.d f=3, p<0.001\right)$ and women who ever informed their partner for using contraceptives $\left(\chi^{2}=76.547, \mathrm{df}=1\right.$, $\mathrm{p}<0.001$ ), while Fisher's exact test revealed a statistically significant association with who decides on the number of children to have $(\mathrm{p}=0.012)$. With regards to the proximate factors, the study revealed the statistical significance of: including contraceptive affordability $\left(\chi^{2}\right.$ $=159.633, \mathrm{df}=1, \mathrm{p}<0.001)$; been sexually active $(\mathrm{p}<0.001)$; the frequency of $\operatorname{sex}(\mathrm{p}<0.001)$; ever used contraceptive before $\left(\chi^{2}=286.669, \mathrm{df}=1, \mathrm{p}<0.001\right)$; the frequency of using contraceptives $(\mathrm{p}<0.001)$ and getting contraceptive when due $\left(\chi^{2}=286.331, \mathrm{df}=1, \mathrm{p}<0.001\right)$. The Fisher's exact test results show a statistically significant association between contraceptive uptake and what women do when they could not have contraceptives from the clinic $(\mathrm{p}<0.001)$. Other factors such as women preference of FP service providers $(\mathrm{p}=0.005)$, having a person to contact about contraceptives $(\mathrm{p}<0.001)$ and what they do when they don't have contraceptives from clinics $(p<0.001)$ were reported to be significant.

Table 4. Socio-cultural and proximate factors associated with contraceptive uptakes

\begin{tabular}{|c|c|c|c|c|c|}
\hline \multirow[b]{2}{*}{ Socio-cultural and proximate factors } & \multicolumn{3}{|c|}{ Current use of contraceptives } & \multirow[b]{2}{*}{$\begin{array}{l}\text { Chi- } \\
\text { square }\end{array}$} & \multirow[b]{2}{*}{ p-value } \\
\hline & $\begin{array}{c}\text { Yes }(n=193) \\
n(\%)\end{array}$ & $\begin{array}{c}\text { No }(n=441) \\
n(\%)\end{array}$ & $\begin{array}{c}\text { Total }(\mathrm{N}=634) \\
\text { n }(\%)\end{array}$ & & \\
\hline \multicolumn{6}{|l|}{ Societies support on use of contraceptive methods } \\
\hline Yes & $101(37.3)$ & $170(62.7)$ & $271(100.0)$ & 10.426 & $0.005^{*}$ \\
\hline No & $74(25.4)$ & $217(74.6)$ & $291(100.0)$ & & \\
\hline I don't know & $18(25.0)$ & $54(75.0)$ & $72(100.0)$ & & \\
\hline \multicolumn{6}{|c|}{ Traditional /cultural beliefs against contraceptive usage } \\
\hline Yes & $108(28.6)$ & $269(78.4)$ & $377(100.0)$ & 1.436 & 0.488 \\
\hline No & $62(33.3)$ & $124(66.7)$ & $186(100.0)$ & & \\
\hline I don't know & $23(32.4)$ & $48(67.6)$ & $71(100.0)$ & & \\
\hline \multicolumn{6}{|c|}{ Partner support on the use of contraceptive methods } \\
\hline Yes & $97(56.1)$ & $76(43.9)$ & $173(100.0)$ & 76.750 & $<0.001^{*}$ \\
\hline No & $67(23.8)$ & $215(76.2)$ & $282(100.0)$ & & \\
\hline I don't know & $29(16.2)$ & $150(83.8)$ & $179(100.0)$ & & \\
\hline \multicolumn{6}{|l|}{ Who decides on contraceptive uptake $(n=481)$} \\
\hline Husband/partner alone & $47(31.5)$ & $102(68.5)$ & $149(100.0)$ & 36.512 & $<0.001^{*}$ \\
\hline Wife alone & $67(50.4)$ & $66(49.6)$ & $133(100.0)$ & & \\
\hline Both wife and husband/partner & $70(51.9)$ & $65(48.1)$ & $135(100.0)$ & & \\
\hline Healthcare providers & $3(10.3)$ & $26(89.7)$ & $29(100.0)$ & & \\
\hline
\end{tabular}




$$
\text { Not using contraceptives } \quad 6(17.1) \quad 29(82.9) \quad 35(100.0)
$$

Are contraceptives harmful or has side effect? $(n=481)$

$\begin{array}{cccc}\text { Yes } & 115(40.6) & 168(59.4) & 283(100.0) \\ \text { No } & 75(39.5) & 115(60.5) & 190(100.0) \\ \text { 't know } & 3(37.5) & 5(62.5) & 8(100.0)\end{array}$

$0.957+$

I don't know

Are contraceptives beneficial? $(\mathrm{n}=481)$

$$
\begin{aligned}
& \text { Yes } \\
& \text { No }
\end{aligned}
$$

Know about Contraceptives

$$
\begin{aligned}
& \text { Yes } \\
& \text { No }
\end{aligned}
$$

Heard of Contraceptives

$$
\begin{aligned}
& \text { Yes } \\
& \text { No }
\end{aligned}
$$

Affordability of contraceptive

$$
\text { Yes }
$$$$
\text { No }
$$

Sexually active

$$
\begin{aligned}
& \text { Yes } \\
& \text { No }
\end{aligned}
$$

Frequency of sex

$$
\text { Every time (everyday) }
$$

Most times (>once per week)

Occasionally (at least twice per month)

Rarely

$$
\text { Never }
$$

Used contraceptive before

$$
\begin{aligned}
& \text { Yes } \\
& \text { No }
\end{aligned}
$$

Frequency of using contraceptives

$$
\begin{gathered}
\text { Every time } \\
\text { Most times } \\
\text { Occasionally } \\
\text { Rarely } \\
\text { Never }
\end{gathered}
$$

Getting contraceptives when due

$$
\begin{aligned}
& \text { Yes } \\
& \text { No }
\end{aligned}
$$

Discuss FP with partner

$$
\begin{aligned}
& \text { Yes } \\
& \text { No }
\end{aligned}
$$

\section{Reasons for not discussing with partners $(n=396)$}

He does not approve it

It is against cultural norms

He will regard me as a player

It is against my religious beliefs
$29(20.9)$

$13(12.3)$

$110(79.1)$

93 (87.7)

$22(46.8)$

94 (90.4)

$10(9.6)$$$
74(18.7)
$$

$119(50.0)$

$322(81.3)$

25 (53.2)

430 (100.0)

51 (100.0)

$481(100.0)$

153 (100.0)

603 (100.0)

31 (100.0)

328 (100.0)

306 (100.0)

$589(100.0)$

45 (100.0)

13 (100.0)

341 (100.0)

$129(100.0)$

106 (100.0)

45 (100.0)

293 (100.0)

341 (100.0)

$286.669<0.001^{*}$

$$
9(100.0)
$$

$42(100.0)$

135 (100.0)

97(100.0)

351 (100.0)
238 (100.0)

396 (100.0)

237 (100.0)

397 (100.0)

139 (100.0)

106 (100.0)

47 (100.0)

$104(100.0)$
$11.997 \quad 0.001^{*}$

$<0.001 \dagger^{*}$

$<0.001$ † $^{*}$

$159.633<0.001^{*}$

$<0.001 \dagger^{*}$

$<0.001$ † $^{*}$

$<0.001 \dagger^{*}$

$286.311<0.001^{*}$

$68.836<0.001^{*}$

$33.405<0.001^{*}$ 
Preference of FP service provider

Female service providers for women

$\begin{array}{ccc}63(24.2) & 197(75.8) & 260(100.0) \\ 31(44.9) & 38(55.1) & 69(100.0) \\ 4(40.0) & 6(60.0) & 10(100.0) \\ 95(32.2) & 200(67.8) & 295(100.0) \\ & & \\ 21(28.0) & 54(72.0) & 75(100.0) \\ 6(16.2) & 31(83.8) & 37(100.0) \\ 8(80.0) & 2(20.0) & 10(100.0) \\ 31(23.0) & 104(77.0) & 135(100.0) \\ 126(35.2) & 232(64.8) & 358(100.0) \\ 1(5.3) & 18(94.7) & 19(100.0)\end{array}$

$0.005 t^{*}$

Male service providers for men

Community based distributors

No sex preference

Person to contact about contraceptives

Husband/partner

Relatives

Male friends

Female friends

Healthcare providers

My parents (mother)

$1(5.3) \quad 18(94.7)$

$19(100.0)$

Who decides on the number of children to have

$\begin{array}{cccc}\text { Husband/partner } & 69(31.4) & 151(68.6) & 220(100.0) \\ \text { Myself } & 75(37.9) & 123(62.1) & 198(100.0) \\ \text { Family/close relatives } & 3(37.5) & 5(62.5) & 8(100.0) \\ \text { Parents } & 3(16.7) & 15(83.3) & 18(100.0) \\ \text { Not in any relationship/marriage } & 6(14.6) & 35(85.4) & 41(100.0) \\ \text { God decides } & 37(24.8) & 112(75.2) & 149(100.0)\end{array}$

Ever informed your partner of using contraceptives

\begin{tabular}{lccccc} 
Yes & $112(53.1)$ & $99(46.9)$ & $211(100.0)$ & 76.547 & $<0.001^{*}$ \\
No & $81(19.1)$ & $342(80.9)$ & $423(100.0)$ & & \\
don't have Contraceptives from clinics & & & \\
rom the pharmacy & $118(55.4)$ & $95(44.6)$ & $213(100.0)$ & & $<0.001+^{*}$ \\
rnative methods & $20(64.5)$ & $11(35.5)$ & $31(100.0)$ & & \\
se any methods & $30(12.9)$ & $203(87.1)$ & $233(100.0)$ & & \\
ner to use protection & $20(13.4)$ & $129(86.6)$ & $149(100.0)$ & & \\
\hline
\end{tabular}

*Statistically significant

† Fisher's Exact test

In Table 5, the multivariate analysis shows that the variables in the model accounted for between $45.3 \%$ - $65.5 \%$ of the variation observed in the outcome variable (use of contraceptives). Women who used contraceptives before to delay or avoid pregnancy were more likely by an odds of 24.416 compared to those who did not use contraceptives before. This was statistically significant $(\mathrm{p}<0.001,95 \% \mathrm{CI}=6.680-89.242)$. The likelihood of women who get contraceptives when due increased by an odds of 7.607 to use contraceptives compared to those who do not get contraceptives when due. This was statistically significant ( $\mathrm{p}<0.001,95 \% \mathrm{CI}=3.096-18.691)$. Women whose reason for not discussing FP with their partner as they will be regarded as a player (promiscuity) were more likely by an odds of 5.974 to use contraceptives compared to those whose reason has been FP usage is against their religious beliefs. This was statistically significant ( $\mathrm{p}=0.029,95 \% \mathrm{CI}=1.196-$ 29.841). 
Table 5. Results of Binary Logistic Regression analysis for FP uptake among reproductive-age women by Socio-cultural and proximate factors

\begin{tabular}{|c|c|c|c|c|c|}
\hline \multirow[b]{2}{*}{ Predictors } & \multirow{2}{*}{$\begin{array}{l}\text { B (regression } \\
\text { coefficient) }\end{array}$} & \multirow[b]{2}{*}{$\begin{array}{c}\text { Adjusted } \\
\text { Odds Ratio }\end{array}$} & \multicolumn{2}{|c|}{ 95\% C.I. for aOR } & \multirow[b]{2}{*}{ P-value } \\
\hline & & & Lower & Upper & \\
\hline \multicolumn{6}{|c|}{ Use contraceptives before to delay or avoid pregnancy } \\
\hline Yes & 3.195 & 24.416 & 6.680 & 89.242 & $<0.001^{*}$ \\
\hline No $(\operatorname{Ref})$ & & 1 & & & \\
\hline \multicolumn{6}{|l|}{ Do you get contraceptives when due? } \\
\hline Yes & 2.029 & 7.607 & 3.096 & 18.691 & $<0.001^{*}$ \\
\hline No $(\operatorname{Ref})$ & & 1 & & & \\
\hline \multicolumn{6}{|c|}{ Reasons for not discussing FP with your partner } \\
\hline He does not approve it & -0.047 & 0.954 & 0.316 & 2.879 & 0.933 \\
\hline It is against cultural norms & -0.192 & 0.826 & 0.229 & 2.980 & 0.770 \\
\hline He will regard me as a player & 1.787 & 5.974 & 1.196 & 29.841 & $0.029^{*}$ \\
\hline It is against my religious beliefs (Ref) & & 1 & & & \\
\hline \multicolumn{6}{|c|}{ Have you ever informed your partner for using contraceptives } \\
\hline Yes & -0.936 & 0.392 & 0.077 & 1.991 & 0.259 \\
\hline No $($ Ref $)$ & & 1 & & & \\
\hline \multicolumn{6}{|l|}{ Are contraceptives beneficial? } \\
\hline Yes & 1.173 & 3.230 & 0.421 & 24.786 & 0.259 \\
\hline No $($ Ref $)$ & & 1 & & & \\
\hline
\end{tabular}

Ref=Reference category, $R^{2}=45.3 \%-65.5 \%, C I=$ Confidence Interval, * statistical significance $p<0.05$

\section{Discussion}

The participants' mean age was similar to that of women of childbearing age in rural Nigeria $[37,38]$. The majority of women were in their reproductive prime age. Similar to Osun State, two-thirds of the women have some types of education up to senior secondary level [39]. Women with no formal education were found to be high, possibly explaining the gender parity. Women's parity has been shown to be less likely with higher educational status. The high parities could be explained by the fact that Islam is the prevalent religion in rural Gambia. The ability of a woman to bear children is seen as a stabilizing influence on her marriage, and in some Gambian cultures, men have to prove their virility by the number of children they have. A study in Nigeria's Edo and Osun states found similar results, with a higher proportion of married participants [38, 40].

The overall contraceptive prevalence rate was $30.4 \%$ while the CPR for women that are married or in the union was $32.1 \%$. The finding is slightly higher than the national modern contraceptive uptake rate at 19\% [31] while remarkedly low among married/inunion women when compared to studies in Kenya [41, 42]. The most common modern contraceptive methods currently used were injectables, pills, and implants. This could be due to expansion or decentralization of reproductive and child health programs in across the length and breadth of the country including the rural communities.

This and other rural studies, women reported their male partners' aversion to FP was a key deterrent, even when they made shared decisions [43]. Men are generally disengaged from and uninterested in reproductive health issues, especially in rural patriarchal societies [44]. The Ghanaian study found that men and women accepted FP equally, pointing to poor spousal communication resulting to an incorrect view of male companions' opinions [45]. Studies in other SSA countries have shown that male involvement in FP can improve marital communications and thereby enhance uptake and persistence of contraceptive usage $[44,46]$. While most males thought that using contraceptives allowed for 
infidelity mostly on woman's part, many argued that shared decision-making and honesty might help reduce some of these doubts and anxieties [47]. However, other scholars argued that research needs to be conducted on male partners' perspectives on contraception [48]. Unmarried young women are exposed to peer pressure that may lead them to participate in risky sexual encounters without their will. Temptations may come from peers or a partner's pressure. Poverty pushed them into having transactional intercourse with older men to meet their basic needs, even if it increased their chance of unwanted pregnancy $[49,50]$. It can also be deduced from these studies that women, especially girls, not being able to protect themselves from coercive sex could also be attributed to both gender and power inequalities, especially in the rural settings.

In terms of socio-cultural and proximate factors, the effect of the previous use of FP to avoid pregnancy, getting FP when due and reasons for not discussing FP with a partner were found to be statistically significant. Not having the partners' approval for utilization of FP service provides a potentially important lens into contraceptive uptake [34]. Weak spousal/partner communications about modern contraception was the main obstacle for women considering it. Men had the power to decide on family size and contraception as head of households. In The Gambia, husbands/partners and wives rarely openly discuss this decision. Most of the time, a husband and wife would discuss and decide on the number of children they wanted, which is usually out of concern for the women's health or the economic burden of raising children. Although women who did not use modern contraceptives understood what they are and where to get them, but their partners were less cognizant of their availability. Mainstream media (radio, television, or print) engagements are an attractive option for promoting FP since they may reach a wider audience and handle topics that are sometimes controversial [51]. Other studies have shown that spousal or peer opposition affects the use of contraception [23]. The type of communication platforms with reference to women's choice greatly depends on the appealing promotional strategies embedded within the accepted societal and cultural value systems [23].

Women whose reason for not discussing FP with their partners for been labeled as a player (promiscuity) were more likely to use contraceptives as compared to religious reasons. In a patriarchal society, wherein males are ultimately responsible for reproductive health decisions, awareness programs must target both husbands and women. The results show that men make the majority of decisions on fertility and fertility control. One of the important reasons in contraceptive use is male decision-making domination. Males should be actors in FP programs to help them grasp the relevance of FP and how to use the various tools. Also, it may minimize the male skepticism towards FP methods that leads to non-users and those who stop using FP due to negative effects. Reducing the distance women must travel to receive FP services may increase utilization. Women's access to hospitals, private clinics, and community-based distributors was a major determinants of current contraceptive use in Lesotho [52]. Affordability, consistency, and commitment to women's contraceptive concerns were also predictors of its usage [23, 53, 54].

\section{Limitations of the Study}

The study was limited to the determination of the level of contraceptive uptake by women and contribution of factors influencing the uptake of FP services only. It did not extend to study of the influence of health system factors on FP uptakes. The information obtained was based on self-reporting and the authenticity of claims may not be readily confirmable. The incorrectly filled questionnaire was minimized by adopting interview administered approach to questionnaire administration. 


\section{Conclusion}

The study population used contraception infrequently. The reasons for not using FP in the feature, past use of FP to avoid pregnancy, getting FP when due, and not discussing FP with partners were determinants of contraceptive use among women of childbearing age in rural communities. Women of younger age, Muslim, those with Arabic education, higher parity, and low monthly income had the lowest uptake of FP. The programme should definitely consider improving the quality of care delivered to acceptors. That is, policymakers and program implementers should prioritize women from rural LGAs/regions. Organizations and governments interested in FP implementation should design programs geared towards the youth and information about FP should be adapted to the community and communicated in a way that everyone can grasp. Women's participation in micro-finance operations, employment possibilities, cash crop agricultural production, and economic empowerment among rural women will enable them to access/afford contraceptives. Furthermore, providers must be adequately trained in counseling, screening, and side-effect management. Spousal dialogue on FP concerns is a key intermediate step towards eventual acceptance and sustained adoption and utilization of FP strategies.

\section{Declarations}

\section{Acknowledgement}

The author would like to express our gratitude to all of our study subjects who were enthusiastic in their active participation throughout the data collection process. The author like to express their gratitude to The Gambian Government, through the Ministry of Higher Education, Research, Science, and Technology (MOHERST), for their financial support all through the process.

\section{Funding}

MOHERST partly supported the fieldwork phase of the study.

\section{Availability of data}

The datasets are available upon request from the author.

\section{Author's contribution}

$\mathrm{AB}$ designed the project, conducted fieldwork, analyzed data, wrote results and the original manuscript. He approved this manuscript and had the final responsibility to submit for publication.

\section{Competing interests}

Not declared

\section{Ethics approval and consent to participate}

The study protocol was approved by University of Benin's Research Ethics Committee, College of Medical Sciences (Ref:CMS/REC/01/COL.3/006) and University of The Gambia's Research and Publication Committee (Ref: \#R017 040). All methods were performed in accordance with the relevant guidelines and regulations. Written informed consent was obtained from participants (signed or thumb-printed), including parents of those between 15 to 17 years old.

\section{Consent for publication}

Not applicable 


\section{References}

[1] WHO (2019) Contraception: Evidence brief. 1-4

[2] Cates W (2010) Family Planning: The essential link to achieving all eight Millennium Development Goals. Contraception 81:460461

[3] Singh S, Darroch JE (2012) Adding It Up: Costs and Benefits of Contraceptive Services Estimates for 2012. Guttmacher Inst United Nations Popul Fund (UNFPA), 201 1-28

[4] Tsui AO, McDonald-Mosley R, Burke AE (2010) Family planning and the burden of unintended pregnancies. Epidemiol Rev 32:152-174

[5] Reynolds HW, Janowitz B, Wilcher R, Cates W (2008) Contraception to prevent HIV-positive births: current contribution and potential cost savings in PEPFAR countries. Sex Transm Infect 84:49-53

[6] Singh S, Darroch JE, Ashford LS, Vlassoff M (2009) Adding it Up: The Costs and Benefits of Investing in Family Planning and Maternal and Newborn Health.

[7] Rutstein SO (2005) Effects of preceding birth intervals on neonatal, infant and under-five years mortality and nutritional status in developing countries: evidence from the demographic and health surveys. Int J Gynaecol Obs 89:7-24

[8] Cleland J, Conde-Agudelo A, Peterson H, Ross J, Tsui A (2012) Contraception and health. Lancet 380:149-56

[9] United Nations Population Fund (2013) Adolescent and Youth Demographics: A Brief Overview. 1-2

[10] United Nations Population Fund (2006) Family planning and young people.

[11] Ahmed S, Li Q, Liu L, Tsui AO (2012) Maternal deaths averted by contraceptive use: an analysis of 172 countries. Lancet (London, England) 380:111-25

[12] Beson P, Appiah R, Adomah-Afari A (2018) Modern contraceptive use among reproductive-aged women in Ghana: prevalence, predictors, and policy implications. BMC Womens Health 18:157

[13] Ganatra B, Gerdts C, Rossier C, et al (2017) Global, regional, and subregional classification of abortions by safety, 2010-14: estimates from a Bayesian hierarchical model. Lancet 390:2372-2381

[14] Guttmacher Institute (2017) Adding It Up: The Costs and Benefits of Investing in Sexual and Reproductive Health 2017. fact sheet, New York Guttmacher Institute, 1

[15] Singh S, Darroch JE (2012) Adding It Up: Costs and Benefits of Contraceptive Services Estimates for 2012. New York

[16] Dansou J (2019) The benefits of family planning (FP) use in Benin: An application of the Demographic Dividend Model (DemDiv). Gates Open Res 3:1110

[17] Kantorová V, Wheldon MC, Ueffing P, Dasgupta ANZ (2020) Estimating progress towards meeting women's contraceptive needs in 185 countries: A Bayesian hierarchical modelling study. PLOS Med 17:e1003026

[18] United Nations (2019) Family Planning and the 2030 Agenda for Sustainable Development Data Booklet.

[19] Das NP, Mishra VK, Saha PK (2001) Does Community Access Affect the Use of Health and Family Welfare Services in Rural India?

[20] Almualm YKA (2007) Knowledge, Attitude and Practice of Husbands towards Modern Family Planning in Mukalla Yemen, University Sains Malaysia. 42-62

[21] Begum S, Nair S, Donta B, Prakasam CP (2014) Prevalence of unmet need for contraception in urban slum communities , Mumbai. Int J Reprod Contraception, Obstet Gynecol 3:627-630

[22] Ibnouf H, Van den Borne H, Maarse J (2007) Utilization of Family Planning services by married Sudanese Women of Reproductive Age. East Mediterr Heal J 13:1376 - 80

[23] Gizaw A, Regassa N (2011) Family planning service utilization in mojo town, Ethiopia: a population based study. J Geogr Reg Plan 4:355-363

[24] Barrow A (2020) A Survey on Prevalence and Knowledge of Family Planning among Women of Childbearing Age in the Provincial Settings of the Gambia: A Descriptive Cross-Sectional Study. Adv Prev Med 2020:1-12

[25] Wood SN, Karp C, Tsui A, et al (2021) A sexual and reproductive empowerment framework to explore volitional sex in subSaharan Africa. Cult Health Sex 23:804-821

[26] World Health Organization (2012) Addressing the Challenge of Women's Health in Africa Report of the Commission on Women's Health in the African Region.

[27] Cohen N, Mendy FT, Wesson J, et al (2020) Behavioral barriers to the use of modern methods of contraception among unmarried youth and adolescents in eastern Senegal: A qualitative study. BMC Public Health 20:1-9

[28] United Nations Population Fund (1994) Evaluation Findings, Quality of Family Planning. 3:2-6

[29] Moronkola OA, Ojediran MM, Amosun A (2006) Reproductive Health Knowledge, beliefs and determinants of contraceptives use among women attending family planning clinics in Ibadan, Nigeria. Africa Heal Sci 6:155 - 159

[30] Gambia Bureau of Statistics (2019) The Gambia Multiple Indicator Cluster Survey 2018, Survey Findings Report. Banjul, The Gambia.

[31] Gambia Bureau of Statistics and ICF (2021) The Gambia Demographic and Health Survey 2019-20. Banjul, The Gambia and Rockville, Maryland, USA: GBoS and ICF.

[32] WHO, UNICEF, UNDP, UNFPA (2015) Gambia National Indicators. 
[33] Gambia Bureau of Statistics (GBOS) and ICF International (2014) Gambia Demographic and Health Survey 2013. GBOS ICF Int $59-89$

[34] Government of The Gambia, World Bank Group: Health Nutrition \& Population (2015) The Gambia Maternal and Child Nutrition and Health Results Project - Baseline Survey Report. 103-115

[35] Gambia Bureau of Statistics (2003) Demographic and Settlement data, 2003 census.

[36] Abramson JH, Gahlinger PM (2002) Computer programs for epidemiologists. J Epidemiol Community Heal 56:959-960

[37] Ogboghodo EO, Adam VY, Wagbatsoma VA (2017) Prevalence and Determinants of Contraceptive Use among Women of Child-Bearing Age in a Rural Community in Southern Nigeria. J Community Med Prim Heal Care 29:97-107

[38] Olugbenga-Bello AI, Adeyemi A, Adeoye O, Salawu M, Aderinoye A, Agbaje M (2016) Contraceptive prevalence and determinants among women of reproductive age group in Ogbomoso, Oyo State, Nigeria. Open Access J Contracept 7:33-40

[39] Oyedokun AO (2007) Determinants of Contraceptive Usage: Lessons from Women in Osun State, Nigeria. J Humanit Soc Sci $1: 1-14$

[40] Odusina E, Ugal D, Olaposi O (2012) Socio-Economic Status, Contraceptive Knowledge And Use Among Rural Women In Ikeji Arakeji, Osun State, Nigeria. Afro Asian J Soc Sci 3:1-10

[41] Republic of Kenya CBS (2009) Kenya Demographic and Health Survey 2008, Nairobi.

[42] Republic of Kenya CBS (2014) Kenya Demographic and Health Survey 2013, Nairobi.

[43] Bogale B, Wondafrash M, Tilahun T, Girma E (2011) Married women's decision making power on modern contraceptive use in urban and rural southern Ethiopia. BMC Public Health 11:1-7

[44] Kabagenyi A, Jennings L, Reid A, Nalwadda G, Ntozi J, Atuyambe L (2014) Barriers to male involvement in contraceptive uptake and reproductive health services: a qualitative study of men and women's perceptions in two rural districts in Uganda. Reprod Health 11:21-32

[45] Eliason S, Baiden F, Quansah-Asare G, Graham-Hayfron Y, Bonsu D, Phillips J, Awusabo-Asare K (2013) Factors influencing the intention of women in rural Ghana to adopt postpartum family planning. Reprod Health 10:2-7

[46] Vouking MZ, Evina CD, Tadenfok CN (2014) Male involvement in family planning decision making in sub-Saharan Africawhat the evidence suggests. Pan Afr Med J 19:1-6

[47] Okwor EU, Olaseha IO (2010) Married Men's Perception about Spousal Use of Modern Contraceptives: A Qualitative Study in Ibadan Northwest Local Government Area, Southwest Nigeria. Int Q Community Health Educ 30:223-238

[48] Izale K, Govender I, Fina J-PL, Tumbo J (2014) Factors that influence contraceptive use amongst women in Vanga health district, Democratic Republic of Congo. Afr J Prm Heal Care Fam Med 6:1-7

[49] Hawkins K, Price N, Mussá F (2009) Milking the cow: Young women's construction of identity and risk in age-disparate transactional sexual relationships in Maputo, Mozambique. Glob Public Health 4:169-182

[50] Jordal M, Wijewardena K, Öhman A, Essén B, Olsson P (2015) ‘Disrespectful men, disrespectable women': Men's perceptions on heterosexual relationships and premarital sex in a Sri Lankan Free Trade Zone - a qualitative interview study. BMC Int Health Hum Rights 15:3-10

[51] Mwaikambo L, Speizer I, Schurmann A, Morgan G, Fikree F (2011) What Works in Family Planning Interventions: A Systematic Review. Stud Fam Plann 42:2-12

[52] Tuonane M, Nyovani JM, Diamond I (2004) Provisions of family planning services in Lesotho. Int Fam Plan Perspect 30:77-86

[53] Pallikadavath S, Stones W, Mackenzie H, Drahota A, Dean T (2012) What kind of family planning delivery mechanisms increase family planning acceptance in developing countries? A mixed method Systematic Review. 1-22

[54] Zainab B, Sharmin S, Islam MN (2001) Factors Affecting Utilization of MCH Services in Bangladesh. J Fam Welf 47:68-78 